\title{
Viticulture under climate change impact: future climate and irrigation modelling
}

\author{
Igor Sirnik $^{1,2}$, Hervé Quénol ${ }^{1}$, Miguel Ángel Jiménez-Bello ${ }^{2}$, Juan Manzano ${ }^{3}$ and Renan Le Roux ${ }^{1}$ \\ ${ }^{1}$ UMR6554 LETG CNRS, Université Rennes 2, place du Recteur Henri le Moal 35043 Rennes Cedex, France \\ ${ }^{2}$ Instituto de Ingeniería del Agua y Medio Ambiente, Universitat Politècnica de València, Camino de Vera s/n, 46022, \\ Valencia, Spain. \\ ${ }^{3}$ Centro Valenciano de Estudios sobre el Riego (CVER), Universitat Politècnica de València, Camino de Vera s/n, \\ 46022, Valencia, Spain
}

\begin{abstract}
Vine is highly sensitive to climate changes, particularly temperature changes, which can be reflected in the quality of yield. We obtained meteorological data from weather station Llíria in viticultural site Valencia DO in Spain from the period 1961-2016 and elaborated the future modelling scenario Representative Concentration Pathways 4.5 (RCP4.5) and RCP8.5 for the period 1985-2100 within the Coupled Model Intercomparison, Project Phase 5 (CMIP5) for daily temperature, precipitation and evapotranspiration. The irrigation requirements (IR) future models for grape varieties Tempranillo and Bobal were elaborated. Temperature and evapotranspiration trends increased during observation period and are estimated to continue rising, according to the future model. Nevertheless, precipitation trend is estimated to decrease according to the model. The future scenarios show increase trend of temperature and evapotranspiration and decrease of precipitation. Total IR for the period $1985-2100$ is expected to increase during growing season months according to the trendline for $16.6 \mathrm{~mm}(\mathrm{RCP} 4.5)$ and $40.0 \mathrm{~mm}$ (RCP8.5) for Tempranillo and $8.2 \mathrm{~mm}$ (RCP4.5) and $30.9 \mathrm{~mm}$ (RCP8.5) for Bobal grape variety. The outcome of this research is important to understand better the future climatic trends in Valencia DO and provides valuable data to face the future climate changes.
\end{abstract}

\section{Introduction}

Atmospheric conditions have strong influence in viticulture $[1,2,3]$. Due to recent climate change impact, irrigation practice in viticulture is becoming a reality in Mediterranean regions to control water condition of vine $[4,5,6]$. There are numerous methods to adjust irrigation with high precision in case of water shortage [7]. Shift of phenological stages of vine and changes of wine characteristics are facts [8], which clearly show recent impact of climate change in viticulture; indeed, the adaptation of viticulture is essential and should be based on future climate models [9]. Many studies were made addressing irrigation methodology in viticulture in Mediterranean environment $[4,10,11]$. The object of this paper is to create the future irrigation models for the period 2005 - 2100 for grape plant in viticultural site Valencia DO. There were several studies addressing irrigation and drought problems in viticulture [12,13]. Only few studies were made addressing the drought and irrigation subject in future climate change scenarios $[1$, 14]. This study was made on two representative grape varieties in viticultural site Valencia DO: Tempranillo and
Bobal. Critical analysis was conducted for the reference period 2000 - 2016, to compare the ETo model calculated with FAO Blaney-Criddle formula with the ETo derived from Penman-Monteith formula [15]. Several studies addressed the evapotranspiration future modelling [16, 17] resulting positive trends of evapotranspiration in the future. According to the comparison statistical analysis, the correction calculations were performed, to correct the ETo model for the period 1985 - 2100. Using the precipitation model at the weather station Llìria, EuroCordex data set, corrected ETo model, single crop coefficient $(\mathrm{Kc})$, crop evapotranspiration (ETc) and effective precipitation, the IR model was elaborated for the period $1985-2100$ using two scenarios RCP4.5 and RCP8.5 [18]. The RCP8.5 scenario was chosen due to its highest radiative forcing increase until the year 2100 among the RCP scenarios, the most "pessimistic" scenario. The RCP4.5 the "optimistic" scenario, was used due to its significantly lower increase for radiative forcing until the year 2100 comparing to the RCP8.5 scenario [19]. The Kc value for grape varieties Tempranillo and 
Bobal, were determined using the results of studies conducted by Instituto Valenciano de Investigaciones

\section{Methodology}

We used the subset EUR-11 of the Euro-Cordex simulations, with spatial resolution $12.5 \times 12.5$ [21] and FAO Blaney-Criddle formula (ALLEN R. et al., 1986), to elaborate reference evapotranspiration model (ETo) for the period 1985 - 2100. By using climate models, we faced a certain level of uncertainty, due to simplified representation of future climate [23]. The Blaney-Criddle formula was used, due to available data set and its robust nature after calibration in comparison to PenmanMonteith formula, which requires higher number of parameters difficult to predict. Climate data were retrieved from the weather station Llíria, located inside of Valencia DO viticultural area, Spain [20]. At the weather station Llìria we retrieved the ETo data set from the period 2000 - 2016, calculated by Penman-Monteith formula (FAO-56 Method), commonly used formula in irrigation calculations [15]. The study assesses future IR by using two scenarios: RCP4.5 and RCP8.5 [19] for the period 1985 - 2100. The ETo model was calculated using the FAO Blaney-Criddle formula at the weather station Llíria for the period $2000-2016$. From the same weather station we retrieved the ETo, calculated by PenmanMonteith formula [24]. We used the temperature and precipitation data set from Euro-Cordex data set [21], [25], retrieved from location of the meteorological station Llíria, located in the eastern part of the viticultural area Valencia DO (Figure 1. Location of the study site Valencia DO (left map) and location of the weather
Agrarias [20].

station Lliria, circled with the black ellipse (right map). Figure 1). The methodology was elaborated in three steps:

1. Elaboration of temperature and precipitation model (1985 - 2100), using Regional Climate Model EuroCordex.

2. Calibration of FAO Blaney-Criddle formula (1) to create ETo model for the period $1985-2100$. The calibration process is defined as calculation of the correction factors $a$ and $b$.

$E T_{0}=\{a+b[P(0.46 T+8.13)]\}\left[1+0.1\left(\frac{E l e v}{1000}\right)\right]$

$E T_{0}$ : estimated reference evapotranspiration, $a$ and $b$ : correction factors [22], $P$ : daily percentage of annual daylight hours, $T$ : daily mean temperature, Elev: elevation of the weather station Llíria.

3. Estimation of crop water requirement for grape variety Tempranillo and Bobal, using a simplified balance model, where soil moisture is assumed to be constant (2).

$$
\text { Necessity of irrigation }=E T c-P e f
$$

ETc: crop evapotranspiration, Pef : effective precipitation. Crop coefficient values (Table 1) were retrieved from IVIA [20].

Table 1. Monthly single crop coefficient $(\mathrm{Kc})$ values for Tempranillo and Bobal variety, maximum quality during growing season.

\begin{tabular}{|l|c|c|c|c|c|c|}
\hline Month & April & May & June & July & August & September \\
\hline Variety & 0 & 0 & 0 & 0.2 & 0.4 & 0.4 \\
\hline Bempranillo, maximum quality & 0 & 0 & 0 & 0.15035 & 0.25059 & 0.25059 \\
\hline
\end{tabular}

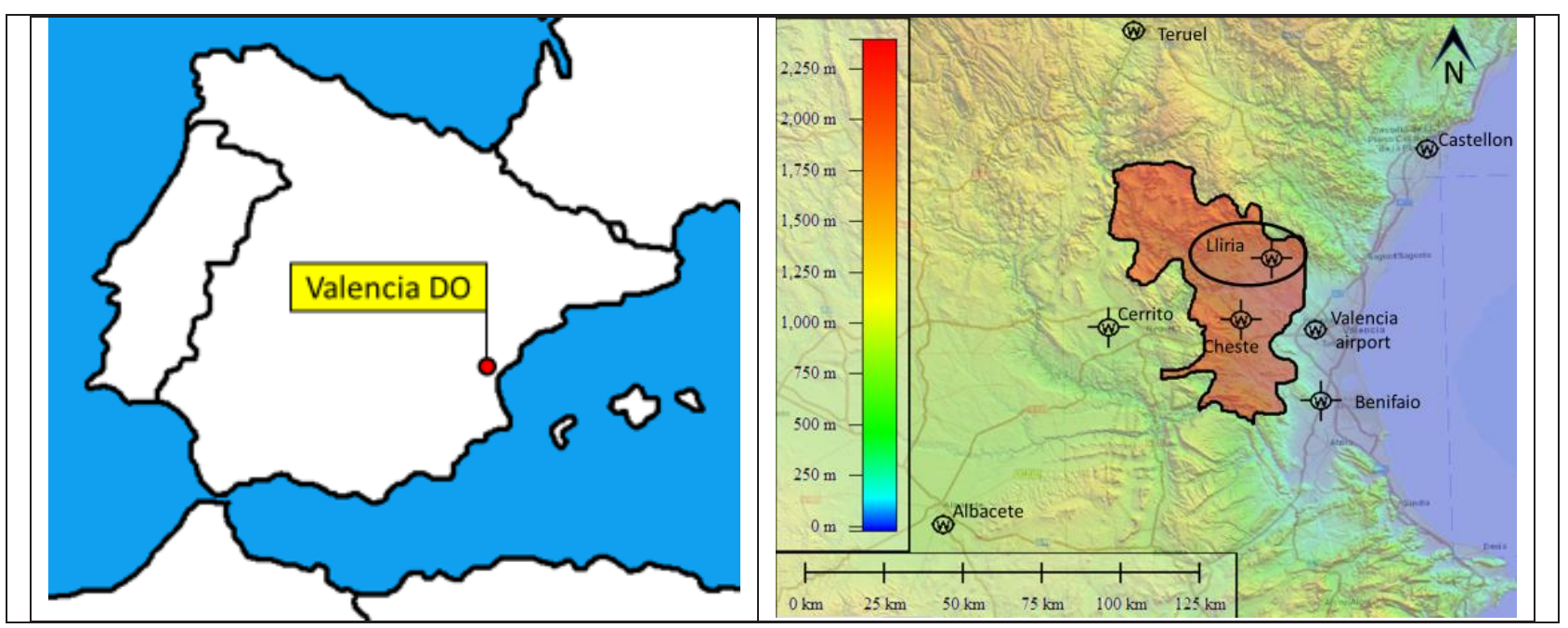

Figure 1. Location of the study site Valencia DO (left map) and location of the weather station Llíria, circled with the black ellipse (right map). Red area represents study site Valencia DO. 


\section{Results and discussion}

Yearly average absolute difference between the ETo derived from Blaney-Criddle formula and ETo derived from observation data, using Penman-Monteith formula during the period 2000 - 2016 was $172.7 \mathrm{~mm}$ (Figure 2.¡Error! No se encuentra el origen de la referencia.). Difference between modelized and observation ETo is caused due to uncertainty of the model and its spatial resolution comparing to the observed data retrieved from one point, weather station Llíria. The absolute difference between the two ETo is notable, nevertheless, they share the same trend. Corrected ETo model for scenarios RCP4.5 and RCP8.5 show stronger correlation with ETo derived from observations during the period $2000-2016$ (Figure 2.). The difference between the RCP4.5 and RCP8.5 ETo scenarios enhances from the year 2057, roughly estimated. Before the year 2057, both RCP scenarios show similar growing tendency. Using the ETo model from the period $1985-2100$, the IR was calculated for Tempranillo and Bobal grape variety according to maximum quality of the grape. In this analysis we considered six months during the grape growing period (from April to end of September). The tendency of IR for Tempranillo and Bobal varieties shows a steady increase during the whole analysis period $1985-2100$ ( Error! No se encuentra el origen de la referencia. and ¿Error! No se encuentra el origen de la referencia.), with an exception in September (Bobal), RCP4.5 scenario, where growth is negative. Stronger increase is noticed in RCP8.5 scenario comparing with RCP4.5 scenario in all six growing season months. Positive IR for Tempranillo was noticed in July, August and September during the whole analysis period and negative in April, May and June (Figure 3). The highest increase shows August $(11.5 \mathrm{~mm})$ for RCP8.5 and September $(5.4 \mathrm{~mm})$ for RCP4.5 scenario, according to the trend line. The lowest increase is noticed in April $(2.4 \mathrm{~mm})$ for RCP8.5 and in May $(0.5 \mathrm{~mm})$ for RCP4.5 scenario, according to the trend line. The most significant difference between the RCP4.5 and RCP8.5 scenarios was detected in August $(6.2 \mathrm{~mm})$ and the lest significant in April $(1.5 \mathrm{~mm})$, where RCP8.5 scenario is superior in both cases. The average increase of IR in the period $1985-2100$, during the growing season months, is $16.6 \mathrm{~mm}$ for RCP4.5 and $40.0 \mathrm{~mm}$ for RCP8.5.

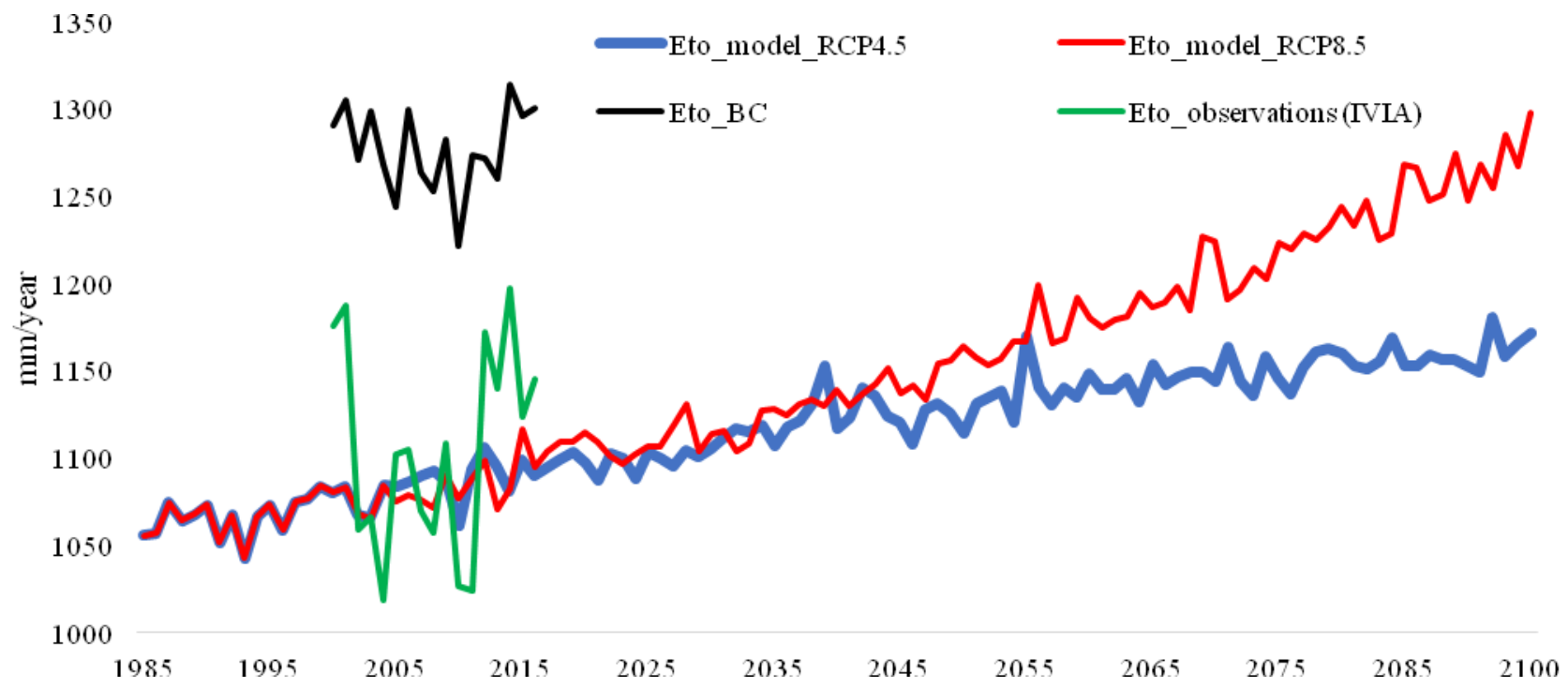

Figure 2. ETo models progress during the period 1985 - 2100, where ETo_model_RCP4.5 and ETo_model_RCP8.5 stand for ETo models using BC formula and Euro-Cordex data set, ETo_observations (IVIA) stands for ETo calculated by Penman-Monteith using observation data set and ETo_BC_2000_2016 stands for ETo model calculated by BC formula using observation data set. 


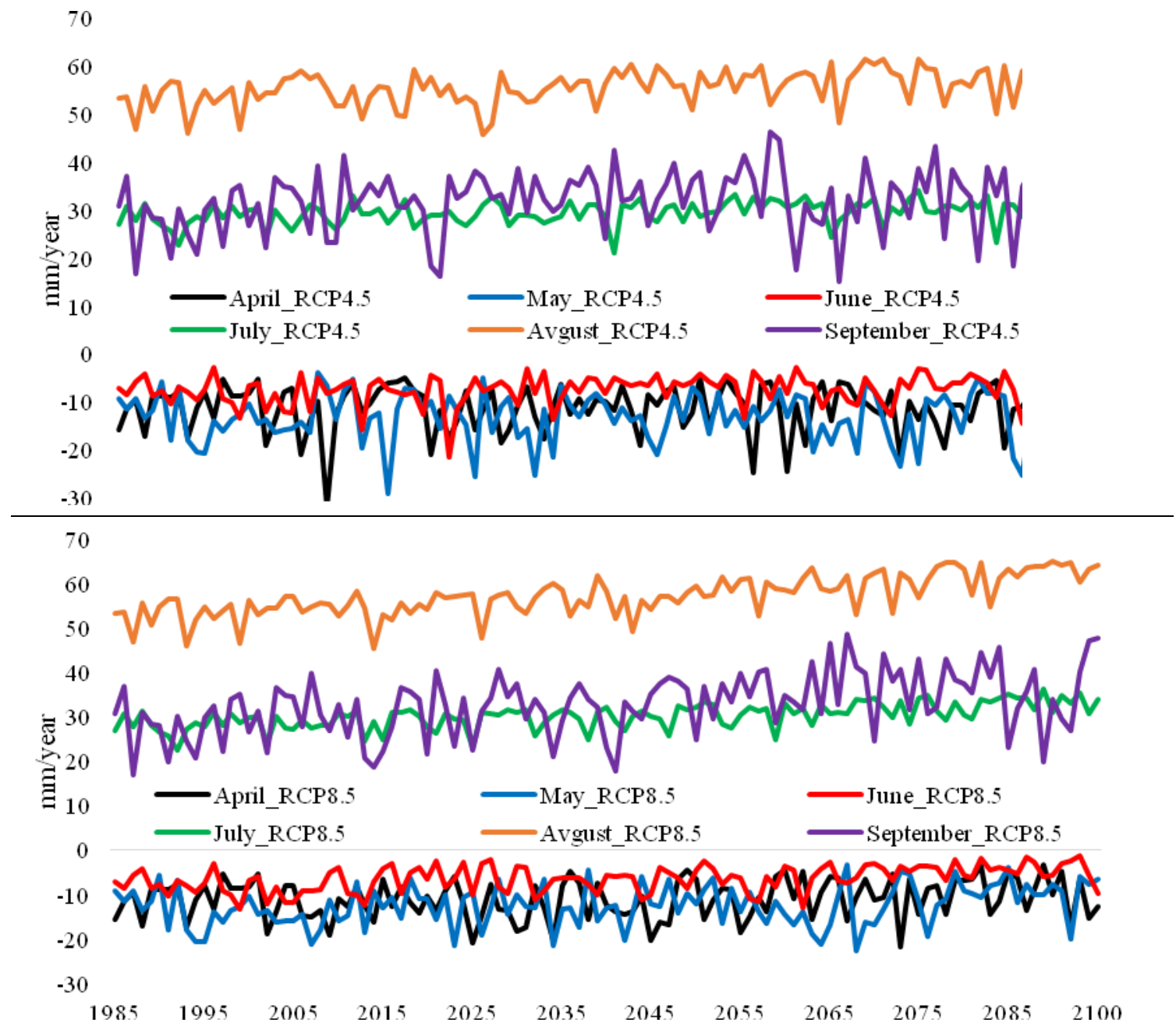

Figure 3. Progress of IR for grape variety Tempranillo, maximum quality, for growing season months. Upper graph represents IR progress according to RCP4.5 scenario and lower graph represents IR progress according to RCP8.5 scenario. Negative values of IR indicate the state, where precipitation is superior than crop evapotranspiration.

Positive IR for Bobal was noticed in July, August and September during the whole analysis period and negative in April, May and June (Figure 4). Exceptions were noticed in September in following years: 1987, 2022 and 2068. The highest increase shows August $(37.8 \mathrm{~mm})$ for RCP8.5 and $5.4 \mathrm{~mm}$ for RCP4.5 scenario, according to the trend line. The lowest increase was noticed in April $(2.4 \mathrm{~mm})$ for RCP8.5 and in September was noticed negative IR $(-0.04 \mathrm{~mm})$ for RCP4.5 scenario, according to the trend line. The most significant difference between the RCP4.5 and RCP8.5 scenarios was detected in September $(7.8 \mathrm{~mm})$ and the least significant in April (1.7 $\mathrm{mm}$ ), where RCP8.5 scenario is superior in both cases. The average increase of IR in the period $1985-2100$, during the growing season months, is $8.2 \mathrm{~mm}$ for RCP4.5 and $31.0 \mathrm{~mm}$ for RCP8.5. The progress of IR for Tempranillo and Bobal grape varieties during 1985 2100 showed similar tendency for all six growing season months. Highest increase of IR was detected in August (RCP8.5 scenario) for Bobal variety, $26.3 \mathrm{~mm}$ higher comparing to August for Tempranillo variety. Negative increase was noticed in September (RCP4.5 scenario) for Bobal variety, which is $0.5 \mathrm{~mm}$ lower than positive increase in May for Tempranillo variety. Total increase of IR for Tempranillo variety, according to RCP8.5 scenario, is $9.0 \mathrm{~mm}$ higher than Bobal variety. Tempranillo variety showed for $8.4 \mathrm{~mm}$ higher increase for RCP4.5 scenario comparing to Bobal variety. 

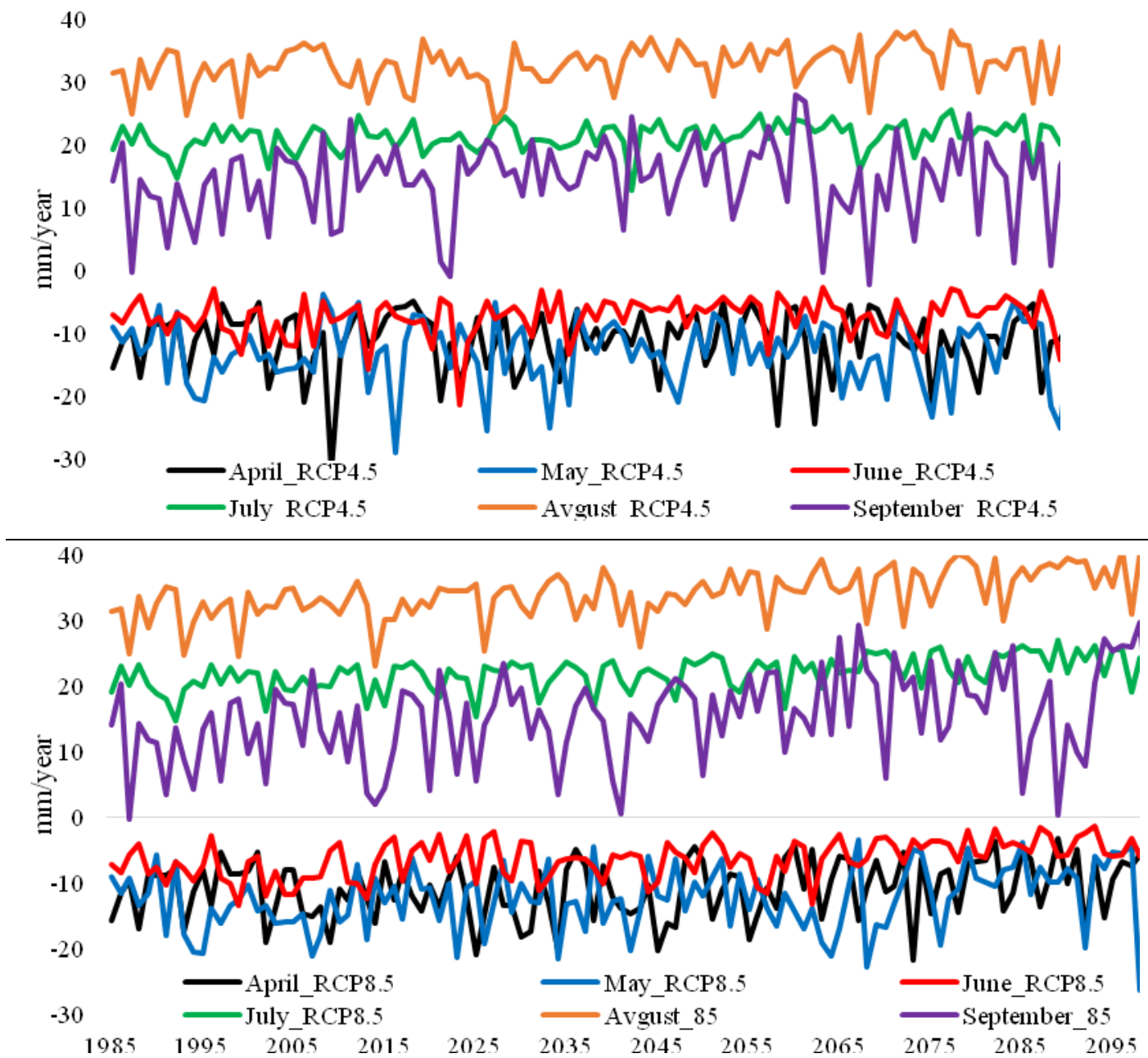

Figure 4. Progress of IR for grape variety Bobal, maximum quality, for growing season months. Upper graph represents IR progress according to RCP4.5 scenario and lower graph represents IR progress according to RCP8.5 scenario. Negative values of IR indicate the state, where precipitation is superior than crop evapotranspiration.

The created ETo models confirm increasing evapotranspiration demand, especially according to the RCP8.5 scenario (Figure 1), which consequentially influences higher future irrigation demand in viticulture. The highest IR is experienced in August for Tempranillo and Bobal variety $(;$ Error! No se encuentra el origen de la referencia. and ¿Error! No se encuentra el origen de la referencia.). Yearly average of IR for the period 1985 - 2100, during growing season months for Tempranillo variety is $14.2 \mathrm{~mm}$ (RCP5.4) and $15.3 \mathrm{~mm}$ (RCP8.5); for Bobal variety is roughly 50\% lower: $6.1 \mathrm{~mm}$ (RCP4.5) and $7.0 \mathrm{~mm}$ (RCP8.5). Negative increase of IR in September can be explained by heavy precipitation, which usually occurs in eastern part of Spain, after the summer, caused by mixing of cold autumn air and hot air above the Mediterranean Sea. The meteorological phenomenon is called "Gota fria" and it occurs on yearly bases [26].

\section{Conclusion}

The irrigation in agriculture is specifically important in eastern Spain, which is expected to experience higher evapotranspiration demands and more extensive droughts periods in the future [27], [28]. According to the created future models for IR for Bobal and Tempranillo grape varieties, IR will increase in the period $1985-2100$ apart from September (Bobal verity, scenario RCP4.5). The increase of IR for Tempranillo variety during the growing season is $16.6 \mathrm{~mm}$ (RCP4.5) and $40.0 \mathrm{~mm}$ (RCP8.5). Bobal variety indicates lower increase of IR: $8.2 \mathrm{~mm}$ for RCP4.5 and $31.0 \mathrm{~mm}$ for RCP8.5. There are two important factors influencing future of irrigation state in viticulture region Valencia DO: temperature and precipitation. According to the future climate models, temperature will continue to rise, and precipitation will diminish, hence both factors do not favour to agriculture needs for viticulture in the future. Future precipitation model, according to the Euro-Cordex model [25], indicates decrease of precipitation in Valencia DO region in the future. Moreover, the study shows significant difference between IR between the Bobal and Tempranillo grape varieties according to the goal of obtaining the maximum quality of grape. Generally, the model can be used for other grape varieties in this viticulture region, however, for more accurate results, the single crop coefficient (Kc) should be modified according to the grape variety. The presented methodology can be 
used in any wine-growing site in to obtain the future irrigation scenarios for Tempranillo and Bobal grape varieties. With calibration of Blaney-Criddle formula and crop coefficient adjustment, this methodology can be used for any plant anywhere in the World. The elaborated IR models provide significant data, to deal with the future impact of climate change in irrigation field in Valencia DO region.

\section{References}

[1] H. Fraga, I. García de Cortázar Atauri, and J. A. Santos, Agric. Water Manag., 196, 66-74, (2018)

[2] J. Tonietto and A. Carbonneau, Agric. For. Meteorol., 124, no. 1-2, pp. 81-97, (2004)

[3] G. V. Jones and G. B. Goodrich, Clim. Res., 35, no. 3, pp. 241-254, (2008)

[4] I. Buesa, D. Pérez, J. Castel, D. S. Intrigliolo, and J. R. Castel, Aust. J. Grape Wine Res., 23, no. 2, pp. 251-259, (2017)

[5] G. V. Jones, Robert E. Davis, Am. J. Enol. Vitic, 51, no. 3, (2000)

[6] P. R. Petrie and V. O. Sadras, Aust. J. Grape Wine Res., 14, no. 1, pp. 33-45, (2008)

[7] G. Rallo, P. González-Altozano, J. ManzanoJuárez, and G. Provenzano, Agric. Water Manag., 180, pp. 136-147, (2017)

[8] V. Guido, Impact of climate change on vitis vinifera L. over Mediterranean area, (2016)

[9] H. Quénol, Iñaki Garcia de Cortazar Atauri, Benjamin Bois, Andrew Sturman, Valérie Bonnardot and Renan Le Roux, J. Int. des Sci. la Vigne du Vin, 51, no. 2, pp. 91-97, (2017)

[10] S. Vanino, G. Pulighe, P. Nino, C. de Michele, S. F. Bolognesi, and G. D’Urso, Remote Sens., 7, no. 11, pp. 14708-14730, 2015

[11] J. M. Costa, M. Vazc, J. Escalonad, R. Egiptob, C. Lopesb, H. Medranod, M.M. Chaves, Agric. Water Manag., 164, pp. 5-18, (2016)

[12] Z. Zsófi, E. Tóth, G. Váradi, D. Rusjan, and B. Bálo, Acta Biol. Szeged., 52, no. 2, pp. 321-322, (2008)

[13] C. van Leeuwen and P. Darriet, J. Wine Econ., 11, no. 1, pp. 150-167, (2016)
[14] P. Döll, Clim. Change, 54, pp. 269-293, (2002)

[15] A. H. L. Penman, Natural Evaporation from Open Water, Bare Soil and Grass, 193, no. 1032, pp. 120-145, (2013)

[16] Y.-P. Xu, S. Pan, G. Fu, Y. Tian, and X. Zhang, J. Geophys. Res. Atmos., 119, no. 5, pp. 21742192, (2014)

[17] E. Obada, E. Alamou, A. Chabi, J. Zandagba, and A. Afouda, Hydrology, 4, no. 3, p. 38, (2017)

[18] IPCC, "IPCC - Intergovernmental Panel on Climate Change," 2017. [Online]. Available: http://www.ipcc.ch/. [Accessed: 18-May-2017]

[19] G. P. Wayne, The Beginner's Guide to Representative Concentration Pathways (RCPs), Skept. Sciece, (2013)

[20] IVIA, "IVIA - Generalitat Valenciana, 2017. [Online]. Available: http://www.ivia.gva.es/. [Accessed: 18-May-2017]

[21] D. Jacob et al., EURO-CORDEX: New highresolution climate change projections for European impact research, Reg. Environ. Chang., 14, no. 2, pp. 563-578, (2014)

[22] R. Allen, W.O. Pruitt and members ASCE, J. Irrig. Drain. Eng., 112, no. 2, pp. 139-155, (1986)

[23] J. Boé, Changement global et cycle hydrologique: Une étude de régionalisation sur la France, p. 278, (2007)

[24] L. G. de Carvalho, A. W. P. Evangelista, K. M. G. Oliveira, B. M. Silva, M. de Carvalho Alves, A. de Sá Júnior, W. L. Miranda, Idesia (Arica), 31, no. 3, pp. 39-47, (2013)

[25] Euro-Cordex, "Euro-Cordex," 2017. [Online]. Available: http://www.euro-cordex.net/.

[Accessed: 18-May-2017]

[26] CHJ, Plan Hidrológico del Júcar 2015-2021, Valencia, (2016)

[27] IPCC, Climate Change 2014 Synthesis Report Summary Chapter for Policymakers, (2014)

[28] M. V. O. Reig, Collective management of irrigation in eastern Spain. Integration of new technologies and water resources, Universitat Politècnica de València, (2015) 